\title{
ORAL SUBMUCOSAL FIBROSIS - A CLINICOPATHOLOGICAL STUDY
}

A.K. Jain, Ritu Nigam, Richa Gupta.

1. Ex Professor \& Head. Department of ENT, G. R. Medical College. Gwalior. Madhya Pradesh.

2. Assistant Professor. Department of ENT, G.R. Medical College. Gwalior. Madhya Pradesh.

3. Ex Post Graduate Student. Department of ENT, G. R. Medical College. Gwalior. Madhya Pradesh.

\section{CORRESPONDING AUTHOR:}

Dr A. K. Jain

PNJ Memorial nursing home,

Opposite civil surgeon office,

Morar, gwalior (mp).

E-mail: entjainak@hotmail.com

ABSTRACT: AIM: To study the prevalence and etiopathogenesis of Oral submucosal fibrosis (OSMF). MATERIAL \& METHODS: The present study was conducted on 206 cases of OSMF attending ENT OPD, G.R. Medical College \& J.A. Group of hospitals, Gwalior, M.P. from January 2010 to January 2012. It was a randomized prospective tertiary hospital based study. RESULT: In the present study Males were predominating with overall M: F ratio 2.67:1. Most of the cases belong to 31-40 year of age group. About $49.52 \%$ patient used heavy spices \& chillies. Maximum cases $62.13 \%$ were gutkha users \& $32.35 \%$ were using gutkha or other products for 10-20 years. About $91.48 \%$ cases chewed \& spitted out the gutkha. It was also observed that $77.65 \%$ cases kept gutkha in mouth bilaterally. About 27.18\% OSMF cases showed association with ulcero-proliferative growth in oral cavity \& oropharynx. CONCLUSION: This article gives an insight into OSMF \& associated lesions in this region of north India and adds to its biological profile.

KEYWORDS - Chewing \& spitting, chillies, gutkha, OSMF.

INTRODUCTION: In 1952 Schwartz (1) described 5 Indian women from Kenya with a condition of oral mucosa including the palate \& pillars of fauces which he called "Atrophica idiopathic (tropica) mucosa oris". Later it was termed oral submucosal fibrosis (OSMF). Other names are "diffuse oral submucosal fibrosis", "idiopathic scleroderma of mouth", "idiopathic palatal fibrosis", sclerosing stomatitis" \& "juxta-epithelial fibrosis".

The WHO definition (2) for an oral precancerous condition is a generalized pathological state of oral mucosa associated with a significantly increased risk of cancer accords well with characteristics of OSMF.

The pathogenesis of the disease is thought to be multifactorial \& chewing of arecanut has been recognized as one of the most important risk factor for OSMF. What makes it most sinister is malignant transformation rate which has been reported to be around $7.6 \%$ over a 17 year period. However there are only few studies of frequency \& clinicopathological feature of OSMF in the Indian population in recent years. Hence this study was carried out to establish relative prevalence \& clinicopathological data on OSMF over a period of 2 years.

MATERIAL \& METHODS: The present study was carried on 206 patient of OSMF attending the outpatient clinic in G.R. Medical College \& J.A. Group of hospitals, Gwalior, M.P. from January 2010 to January 2012 for oral diseases. The OSMF cases were diagnosed as per predefined clinical criteria. As per proforma detailed information of all cases such as age, sex, 
socioeconomic status ,oral hygiene condition , amount of spices \& chillies, nutritional status, any chewing habit of gutkha \& other areca nut products \& duration of keeping in mouth, duration of habit, frequency of chewing, style of chewing, mouth opening etc was noted. Clinical examination of cases was performed examining factor such as inadequate opening of mouth, blanching of mouth \& other associated lesions.

RESULTS \& DISCUSSION: In present study $72.8 \%$ cases were males with overall M: F ratio of 2.67:1 with a general trend towards male preponderance . A study by Chaturvedi $V$ et al (1991) reveals similar observation. Wahi et al (3) reported M: F ratio of 2:1. Male predisposition in our study could be due to easy accessibility of gutkha \& other products to males than females in our society \& probably females feel uncomfortable in purchasing gutkha products. Also financial administration is not in the hands of most females limiting their access to such gutkha products.

It was found that majority of cases (31.09\%) belong to 31- 40 year age group. The youngest case was 20 years of age \& oldest case was 80 years. OSMF has been traditionally reported in middle age group i.e. second to fourth decade $(4,5)$. Shah \& sharma (1998) also reported majority of cases from 21-40 year age group. The prevalence in young age group might be due to easy availability of tobacco in each \& every corner of society \& residential area.

Majority (67.96 \%) of cases belong to low socioeconomic status. Ramanathan (1981), Shiau \& kwan (1979) found that most of OSMF cases from India were of low socioeconomic group. This observation might be due to low cost coupled with lack of health consciousness \& long constant working hours in laborer class of population of Madhya Pradesh.

Among 206 cases $49.52 \%$ cases used heavy spices \& chillies as compared to $2.91 \%$ cases with no use (Table no. 1). Rajendran et al (6), Pillai et al (1992), Mcgurk \& crag et al (1984) have reported that use of spices \& chillies as one of predisposing factors of OSMF. Capsaicin i.e. vanillylmandelic acid of 8-methyl-6 nonemic acid is active ingredient of chillies play an etiological role in OSMF. This might be due to excessive use of more spices \& chillies to make food tasty in our country.

It was also observed that $45.63 \%$ cases had poor nutritional value in their food while $40.78 \%$ \& $13.59 \%$ cases had average \& good nutrition values. Rajendran et al (6) reported that vitamin \& iron deficiency together with malnourished state of host leads to derangement in inflammatory reparative response of lamina propria with resultant defective healing \& scarification which ultimately leads to OSMF.

Habitual chewing of gutkha \& other arecanut product plays a major role in etiology of OSMF. About $62.14 \%$ cases used gutkha alone in comparison to $22.33 \%$ case with multiple habits like gutkha with arecanut, paan masala etc, $5.83 \%$ using paan masala, $0.97 \%$ arecanut alone. About $7.76 \%$ cases showed bidi consumption alone \& $0.97 \%$ cases had no such habits (Table no. 2). This might be due to easy access, effective price changes, market strategies, upsurge in popularity of commercially prepared gutkha or tobacco preparations \& its widely known habit forming property leading to addiction.

Babu et al (7) showed that people were more addicted to gutkha than any other related arecanut \& tobacco products such as paan, paan masala etc \& found strong association between gutkha chewing \& OSMF. The reason attributes to fact that the commercially available products as above are concentrated freeze dried \& have higher dry weight concentration of pathology causing irritants in comparison to traditionally prepared home made products like paan masala. Dry tobacco absorbed by mucosa in more amounts produces addiction to patients \& consequently more suffering manifestation \& severity of disease. 
Gupta \& Ray (8) observed that arecanut with smokeless tobacco cause earlier onset of disease as compared to arecanut alone.

The cases $(32.35 \%)$ especially with habits with duration of 10-20 years were more prone to develop OSMF (Table no. 3). Mcgurk \& crag (9) reported that most of cases of Indian origin living in UK developed OSMF within the period of 5 years of chewing arecanut \& tobacco. Babu et al (1996), Shah \& Sharma et al reported onset of OSMF as early as 4 years after chewing habit of tobacco \& arecanut.

About $39.36 \%$ cases kept gutkha for 10-15 minutes (Table no. 4). Also $37.23 \%$ cases showed frequency of chewing 5-10 gutkha pouches per day (Table no. 5) .The duration \& frequency both seemed to be related to development of OSMF unlike Shah et al who found that frequency rather than total duration was important.

As per style of chewing $91.49 \%$ cases showed chewing \& spitting in comparison to $5.3 \%$ \& $3.9 \%$ with habit of chewing \& swallowing and both chewing \& spitting \& chewing \& swallowing respectively. Also $77.66 \%$ cases reported bilateral chewing of gutkha with $14.89 \%$ \& $7.45 \%$ on right \& left side respectively. This is in accordance with finding of Mukherji \& Biswas (10) \& Ramanathan (11).

Among 206 cases $63.12 \%$ had reported to be OSMF alone. About 27.18\% OSMF cases showed association with ulceroproliferative growth in oral cavity \& oropharynx, $6.79 \%$ OSMF cases showed association with leukoplakia, \& $2.91 \%$ cases with erythroplakia (Table no. 6).

CONCLUSION: The present study thus demonstrated that gutkha use is the main etiological factor which play major role in development of OSMF. Unlike previous studies the disease was reported earlier most probably due to initiation of tobacco chewing at an early age due to its easy availability and its prolonged and frequent use thereafter. Also increased awareness among people might be responsible for early reporting of patients with OSMF.

Like previous studies lower S.E. status is most commonly involved most probably because of lower cost of chewable tobacco and poor intake of fruits and vegetables in this section of people. Also it was observed that nutritional deficiencies may not play a major role but it could synergise the symptomatology by contributing to epithelial atrophy. The use of heavy spices \& chillies was also found to be associated with the disorder.

Even though length of follow up was short in our study but more studies would provide encouraging \& desirable results for early diagnosis of this condition \& its management.

Consent: Written informed consent was obtained from the all patients for publication of this case study.

Funding: None

Conflict of interest: None

\section{REFERENCES:}

1. Herranz-Gonzalez J et al (1991) Esophageal foreign bodies in adults. Otolaryngol Head Neck Surg ; 105: 649-654.1. Schwartz J. (1962) Atrophica Idiopathica (Tropica) mucosae oris. Demonstrated at Eleventh International Dental Congress, London 1952 (cited by Sirsat \& Khanolkar) Indian Journal Medicine;16:189-197.

2. World Health Organization (1980) Guide to epidemiology and diagnosis of oral mucosal diseases and conditions. Community dental oral epidemiology; 8:1-26.

3. Wahi PN, Kapoor VL, Luthra UK (1966) Submucosal fibrosis of the oral cavity: Studies on Epidemiology. Bull WHO; 35: 793-9. 
4. Pindborg JJ, Mehta FS, Gupta PC (1968) Prevalance of oral submucosal fibrosis among 50,915 Indian villagers. British Journal Cancer; 22:646-654.

5. Gurk M, Craig GT (1984) Oral submucosal fibrosis: two cases of malignant transformation in Asian immigrants to the UK. British Journal oral Maxillofacial surgery : 22:56-64.

6. Rajendran R (1994) Oral submucosal fibrosis: Etiology, pathogenesis and future research. Bull WHO; 72:985-86.

7. Babu S, Bhat RV, Kumar PU et al (1996) A comparative clinicopathological study of Oral submucosal fibrosis in habitual chewers of paanmasala and betel quid. Clinical toxicology: 34:317-22.

8. Gupta PC, Ray CS (2003) Smokeless tobacco and health in India and South Asia. Respirology : 8:419-31.

9. McGurk M, Craig GT (1984) OSMF- Two cases of malignant transformation in Asian immigrants to the United Kingdom. British Journal Oral Maxillofacial surgery : 22:56-64.

10. Mukherji Al, Biswas SK (1972) Oral submucosal fibrosis - A search for etiology. Indian Journal of Otolaryngology 24:11.

11. Ramanathan K (1981) OSMF - An alternative hypothesis as to its causes. Med J Malaysia; 36: 243-5.

Table no. 1: As per quantity of spices used

\begin{tabular}{|l|l|l|l|}
\hline S.No. & Quantity & Number & Percentage \\
\hline 1. & No spices & 6 & $2.91 \%$ \\
\hline 2. & Mild & 68 & $33.01 \%$ \\
\hline 3. & Moderate & 30 & $14.56 \%$ \\
\hline 4. & Heavy & 102 & $49.52 \%$ \\
\hline & Total & 206 & $100 \%$ \\
\hline
\end{tabular}

Table no. 2: As per Gutkha use \& other products

\begin{tabular}{|l|l|l|l|}
\hline S.No. & Addiction & Number & Percentage \\
\hline 1. & None & 2 & $0.97 \%$ \\
\hline 2. & Gutkha alone & 128 & $62.14 \%$ \\
\hline 3. & Gutkha \& other products & 46 & $22.33 \%$ \\
\hline 4. & Paan masala & 12 & $5.83 \%$ \\
\hline 5. & Bidi alone & 16 & $7.76 \%$ \\
\hline 6. & Arecanut alone & 2 & $0.97 \%$ \\
\hline & Total & 206 & $100 \%$ \\
\hline
\end{tabular}

Table no. 3: As per duration of use of Gutkha $\&$ other products

\begin{tabular}{|l|l|l|l|}
\hline S.No. & Duration & Number & Percentage \\
\hline 1. & $<1$ year & 0 & $0 \%$ \\
\hline 2. & $1-5$ year & 50 & $24.51 \%$ \\
\hline 3. & $5-10$ year & 56 & $27.45 \%$ \\
\hline 4. & $10-20$ year & 66 & $32.35 \%$ \\
\hline 5. & $>20$ year & 32 & $15.69 \%$ \\
\hline & Total & 204 & $100 \%$ \\
\hline
\end{tabular}


Table no. 4: As per duration of keeping Gutkha \& other products

\begin{tabular}{|l|l|l|l|}
\hline S.No. & Duration & No. & Percentage \\
\hline 1. & $<5 \mathrm{~min}$ & 10 & $5.32 \%$ \\
\hline 2. & $5-10 \mathrm{~min}$ & 54 & $28.72 \%$ \\
\hline 3. & $10-15 \mathrm{~min}$ & 74 & $39.36 \%$ \\
\hline 4. & $>15 \mathrm{~min}$ & 50 & $26.6 \%$ \\
\hline & Total & 188 & $100 \%$ \\
\hline
\end{tabular}

Table no. 5: As per frequency of Gutkha use \& other products

\begin{tabular}{|l|l|l|l|}
\hline S.No. & Frequency & No. & Percentage \\
\hline 1. & $<2$ pouch / day & 22 & $11.7 \%$ \\
\hline 2. & $2-5$ pouch / day & 66 & $35.12 \%$ \\
\hline 3. & $5-10$ pouch /day & 70 & $37.23 \%$ \\
\hline$\underline{4 .}$ & $\geq 10$ pouch / day & 30 & $15.95 \%$ \\
\hline & Total & 188 & $100 \%$ \\
\hline
\end{tabular}

Table no. 6: As per type of Lesion

\begin{tabular}{|l|l|l|l|}
\hline S.No. & Oral cavity lesion & Number & Percentage \\
\hline 1. & OSMF alone & 130 & $63.12 \%$ \\
\hline 2. & OSMF + Ulceroproliferative growth & 56 & $27.18 \%$ \\
\hline 3. & OSMF + Leukoplakia & 14 & $6.79 \%$ \\
\hline 4. & OSMF + Erythroplakia & 6 & $2.91 \%$ \\
\hline & Total & 206 & $100 \%$ \\
\hline
\end{tabular}

